\title{
miR-200b mediates post-transcriptional repression of ZFHX1B
}

\author{
NANNA RØNBJERG CHRISTOFFERSEN, ${ }^{1}$ ASLI SILAHTAROGLU, ${ }^{2}$ ULF ANDERSSON ØROM, ${ }^{1}$ \\ SAKARI KAUPPINEN, ${ }^{2}$ and ANDERS H. LUND ${ }^{1,3}$ \\ ${ }^{1}$ Biotech Research and Innovation Centre, DK-2200 Copenhagen, Denmark \\ ${ }^{2}$ Wilhelm Johannsen Centre for Functional Genome Research, Department of Cellular and Molecular Medicine, \\ University of Copenhagen, DK-2200 Copenhagen N, Denmark \\ ${ }^{3}$ Faculty of Health Sciences, University of Copenhagen, Copenhagen, Denmark
}

\begin{abstract}
MicroRNAs have important functions during animal development and homeostasis through post-transcriptional regulation of their cognate mRNA targets. ZFHX1B is a transcriptional repressor involved in the TGF $\beta$ signaling pathway and in processes of epithelial to mesenchymal transition via regulation of E-cadherin. We show that Zfhx1b and miR-200b are regionally coexpressed in the adult mouse brain and that miR-200b represses the expression of $Z$ fhx $1 b$ via multiple sequence elements present in the 3 '-untranslated region. Overexpression of miR-200b leads to repression of endogenous ZFHX1B, and inhibition of miR-200b relieves the repression of ZFHX1B. In accordance with these findings, miR-200b regulates the activity of the E-cadherin promoter.
\end{abstract}

Keywords: microRNA; translational repression; E-cadherin; miR-200b; ZFHX1B

\section{INTRODUCTION}

ZFHX1B is a transcriptional repressor of the ZFH-1 family that acts as a downstream mediator of TGF $\beta$ and BMP signaling (Verschueren et al. 1999; Postigo 2003). ZFHX1B is widely expressed in humans and mice, most prominently in the heart and in neural tissues (Yamada et al. 2001; Bassez et al. 2004). Mutations causing ZFHX1B haploinsufficiency during embryogenesis form the genetic basis of Mowat-Wilson syndrome, characterized by dysmorphic facial features, mental retardation, microcephaly, seizures, and variable organ malformations (Cacheux et al. 2001; Wakamatsu et al. 2001; Dastot-Le Moal et al. 2007). Genetic ablation of $Z f h x 1 b$ in mice is embryonically lethal at E9.5-E10.5, and the mice exhibit developmental defects in the formation of the neural crest (Higashi et al. 2002; Van de Putte et al. 2003). The ZFHX1B protein has two zinc-finger clusters that bind to conserved E-boxes in promoter regions of its target genes, which include Brachyury, E-cadherin, and $\alpha 4$-integrin (Remacle et al. 1999;

Reprint requests to: Anders H. Lund, Biotech Research \& Innovation Centre, Ole Maaløes Vej 5, DK-2200 Copenhagen, Denmark; e-mail: anders.lund@bric.dk; fax: (+45) 35325669.

Article published online ahead of print. Article and publication date are at http://www.rnajournal.org/cgi/doi/10.1261/rna.586807.
Verschueren et al. 1999). Dynamic down-regulation of E-cadherin expression leading to epithelial-mesenchymal transition and migratory cell behavior is essential to early development and tissue formation (Shook and Keller 2003), and aberrant E-cadherin expression caused by lack of Zfhx1b is thought to contribute to the developmental defects in the $Z f h \times 1 b^{-l-}$ embryos (Van de Putte et al. 2003). Furthermore, elevated ZFHX1B expression correlates with reduced E-cadherin expression in certain cancers (Rosivatz et al. 2002; Elloul et al. 2005) and has been implicated in carcinoma progression by means of its ability to repress E-cadherin and induce epithelial-mesenchymal transition (Comijn et al. 2001; Rosivatz et al. 2002; Miyoshi et al. 2004; Maeda et al. 2005).

MicroRNAs (miRNAs) are an abundant class of small noncoding RNA molecules that regulate gene expression posttranscriptionally (Jackson and Standart 2007). miRNAs are transcribed by RNA polymerase II as long primary transcripts (Cai et al. 2004; Lee et al. 2004) that are processed in multiple steps into cytoplasmic $\sim 22$-nt duplexes (Hutvagner et al. 2001; Ketting et al. 2001; Lee et al. 2003; Yi et al. 2003; Bohnsack et al. 2004; Lund et al. 2004). The duplex is loaded into a ribonucleoprotein particle, miRISC, where unwinding of the duplex enables the mature singlestranded miRNA to base-pair with its target mRNA (Kim and Nam 2006). The majority of mammalian miRNAs are 
thought to recognize their targets by base-pairing of the miRNA seed region (bases $2-8$ at the $5^{\prime}$ end) with one or more sites of perfect complementarity in the $3^{\prime}$ untranslated region (UTR) of the target mRNA (Doench and Sharp 2004; Wang et al. 2006).

miRNA-mediated repression appears to occur by at least two different mechanisms, resulting either in degradation of mRNA or inhibition of mRNA translation. miRNAs mediate RNAi-like cleavage of targets with perfect complementarity, as demonstrated for miR-196 and its endogenous HOXB8 target (Yekta et al. 2004). In addition, miRNAs with incomplete target complementarity can promote target degradation, albeit by different mechanisms (Bagga et al. 2005; Jing et al. 2005; Wu et al. 2006). Other studies indicate that miRNAs, rather than affecting mRNA stability, inhibit mRNA translation at the step of initiation (Humphreys et al. 2005; Pillai et al. 2005; Wang et al. 2006) or elongation (Petersen et al. 2006). The apparent inconsistency of these studies could reflect the existence of several mechanisms for miRNA-mediated repression, which may not be mutually exclusive (Pillai 2005; Petersen et al. 2006; $\mathrm{Wu}$ et al. 2006). Individual miRNAs are thought to influence signaling pathways to affect cell proliferation, differentiation, and death as well as developmental timing (Ambros 2004). In addition, miRNAs may function as a fine-tuning mechanism by dampening the translation of mRNAs outside their expression boundaries (Cohen et al. 2006; Hornstein and Shomron 2006).

As ZFHX1B has important functions during embryogenesis and in a number of human diseases, we set out to investigate a putative role for miRNAs in the regulation of ZFHX1B. In this study we identify miR-200b as a posttranscriptional regulator of ZFHX1B and demonstrate the ability of miR-200b to affect the promoter activity of the ZFHX1B target gene E-cadherin.

\section{RESULTS AND DISCUSSION}

The ZFHX1B mRNA contains a 1.4-kb 3'-UTR with putative binding sites for many miRNAs. Sequence inspection revealed the presence of five sequence elements (S1-S5) complementary to the seed region of miR-200b (nt 2-8). Of these sites, S1 and S3-5 are predicted miR-200b binding sites by TargetScan (Lewis et al. 2005), S4 and S5 are predicted by the miRBase Targets database (Griffiths-Jones et al. 2006), whereas S2 are not predicted binding sites by these databases. We found all five miR-200b complementary sites in the Zfhxlb $3^{\prime}$ UTR to be highly conserved across several species, supporting a biological relevance of these sequence motifs (Fig. 1). To investigate if $Z f h x l b$ and miR-200b are expressed in the same regions of the mouse brain we performed fluorescent in situ hybridization of miR-200b on sagittal sections of adult mouse brain to compare it with previous reports of $Z f h x 1 b$ expression. $Z f h \times 1 b$ is strongly expressed in the pyramidal cell layer and

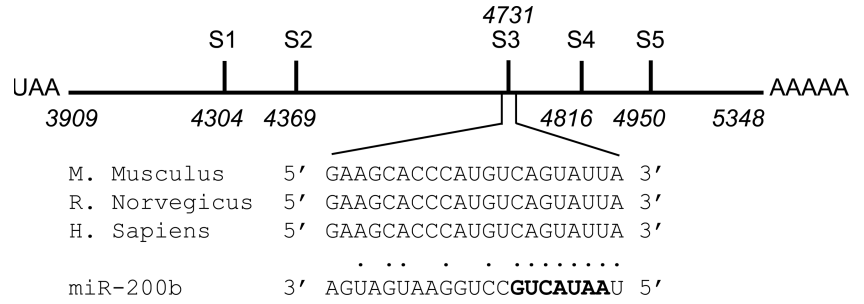

FIGURE 1. miR-200b binding sites in the Zfhxlb $3^{\prime}$-UTR are conserved across species. Schematic representation of the mouse Zfhxlb 3'-UTR containing five potential binding sites for miR-200b (S1-S5), based on occurrence of the complementary miR-200b seed region, CAGUAUU. Numbers refer to positions in Ensembl transcript ENSMUST00000076836. Alignment of a predicted miR-200b binding site (S3) in the ZFHX1B 3'-UTR with complete conservation across three mammalian species is shown as an example. The mature sequence of miR-200b is conserved across the shown species. The seed region of miR-200b is shown in bold.

dentate gyrus of the hippocampal formation as well as the cerebral and cerebellar cortex (Allen Brain Atlas 2004). As evident from Figure 2, the expression pattern of miR-200b overlaps that of $Z f h x l b$ in several regions of the brain, including the hippocampus and the cerebellum. The observed regional coexpression of the Zfhxlb mRNA and miR-200b lends in vivo relevance to the predicted interaction between the molecules.

The ability of miR-200b to bind and regulate the 3 '-UTR of $Z f h x 1 b$ was evaluated using luciferase reporter assays. A $1-\mathrm{kb}$ fragment of the mouse Zfhxlb $3^{\prime}$-UTR was cloned into a pGL3-control vector, placing the $3^{\prime}$-UTR with the five potential miR-200b binding sites downstream of luciferase (pGL3 S1-5). Cotransfections of HEK293 cells with pGL3 S1-5 and concentrations of miR-200b ranging from $2.5 \mathrm{nM}$ to $30 \mathrm{nM}$ resulted in a dose-dependent repression of the reporter (Fig. 3A). Repression was specific to miR-200b as a mutated version of miR-200b containing two point mutations in the seed region failed to repress, as did a structurally unrelated miRNA, miR-10a (Fig. 3A). The repression was furthermore dependent on the $3^{\prime}$ UTR of $Z f h x 1 b$, as miR-200b did not affect the expression of the pGL3 control vector (Fig. 3B).

To analyze the importance of individual miR-200b binding sites for the $3^{\prime}$ UTR-dependent regulation of luciferase, fragments containing $\mathrm{S} 1-2$ and $\mathrm{S} 3-5$ were subcloned in pGL3. HEK293 cells were cotransfected with each of the reporter constructs and $10 \mathrm{nM}$ of miR-200b or mutated miR-200b (Fig. 3B). miR-200b, but not the mutated control, caused significant repression of both constructs $(P<0.001)$, indicating that the Zfhxlb 3'-UTR contains several biologically relevant miR-200b binding sites. In order to determine the mechanism for repression of the luciferase reporter, we quantified the mRNA levels (Fig. 3C). miR-200b caused a significant decrease in the amount of all three luciferase reporters $(P<0.001)$. As none of the putative binding sites predict annealing between miR-200b 


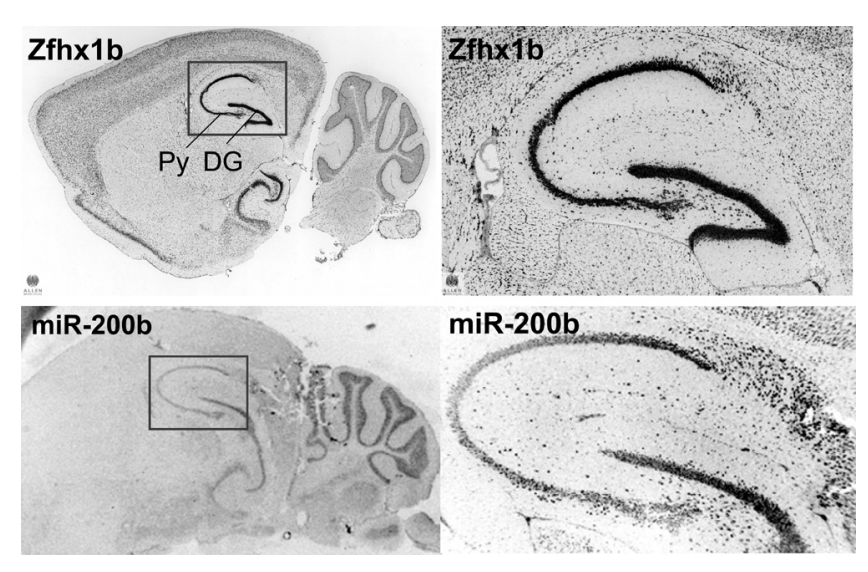

FIGURE 2. Expression of miR-200b and Zfhxlb mRNA in the brain. (Top panel) Sagittal section of adult mouse brain hybridized with an antisense RNA probe for Zfhxlb (Allen Brain Atlas 2004). (Bottom panel) Sagittal section of adult mouse brain hybridized with an antisense LNA-modified oligonucleotide probe for miR-200b. Both genes are expressed in the neocortex, pyramidal cell layer, and dentate gyrus of the hippocampal formation as well as in the granular layer of cerebellum. (Py) Pyramidal cell layer; (DG) Dentate gyrus.

and the $Z f h x 1 b$ mRNA around nucleotides 10-11 relative to the $5^{\prime}$ end of the miRNA, we speculate that the mRNA degradation involves mRNA deadenylation and destabilization rather than Ago2-mediated cleavage (Elbashir et al. 2001).

Having established the ability of miR-200b to mediate repression of luciferase via the Zfhxlb $3^{\prime}$-UTR, we next assayed its capacity to regulate the endogenous ZFHX1B protein. To this end, we transfected the human breast cancer cell line MDA-MB-435S, expressing high levels of ZFHX1B (Comijn et al. 2001), with miR-200b, control miRNA, or a pool of siRNAs directed against ZFHX1B and analyzed protein expression by Western blotting. As evident from Figure 3D,E, miR-200b markedly reduced ZFHX1B protein and mRNA levels compared to mock transfected cells. In contrast, none of the control miRNAs repressed ZFHX1B. Importantly, blocking endogenous miR-200b by transfection with a specific LNA-modified inhibitor resulted in an increase in the level of endogenous ZFHX1B (Fig. 3D), thereby supporting the notion that miR-200b regulates ZFHX1B in vivo.

To investigate the biological significance of ZFHX1B regulation by miR-200b we assayed the effect of miR-200b using an E-cadherin promoter construct, a well-established ZFHX1B target. We used a luciferase reporter construct containing $227 \mathrm{nt}$ of the human E-cadherin promoter including the E-box binding sites for ZFHX1B (Grooteclaes and Frisch 2000) and tested the ability of $m i R-200 b$ to cause derepression of the E-cadherin promoter. As expected, cotransfections of HEK293 cells with the E-cadherin promoter construct and a Zfhxib expression vector caused repression of the E-cadherin promoter (Fig. 4). Conversely, siRNA-mediated knockdown of endogenous ZFHX1B relieved repression of the promoter construct. In agreement with a role for miR-200b in regulation of ZFHX1B, cotransfections of the E-cadherin reporter with miR-200b resulted in a significant derepression of the reporter $(P<0.001)$. This effect was caused specifically by miR$200 \mathrm{~b}$, since cotransfections with miR-10a did not influence the E-cadherin reporter. ZFHX1B has been shown to bind and regulate the E-cadherin promoter through the two E-boxes present in the proximal promoter (Remacle et al. 1999). Overexpression of Zfhxlb or transfection with miR-200b only marginally affected a mutant E-cadherin promoter in which both E-box motifs were altered by point mutation (Fig. 4). This result supports the involvement of miR-200b in the regulation of E-cadherin via ZFHX1B, although we cannot exclude that $m i R-200 b$ may also affect E-cadherin through routes parallel to ZFHX1B repression.

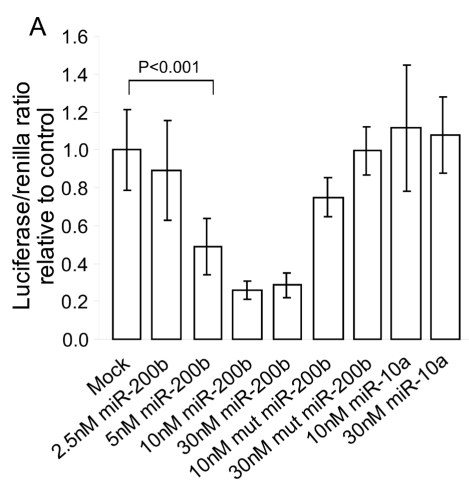

B

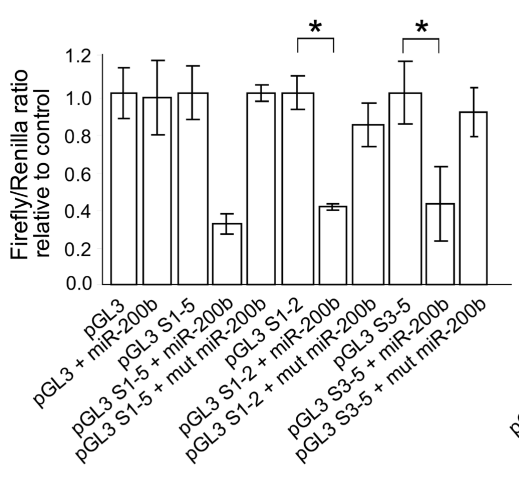

D

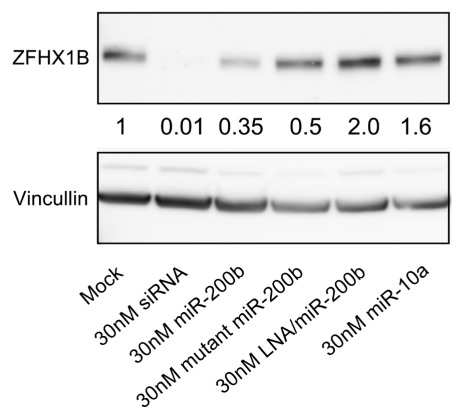

C
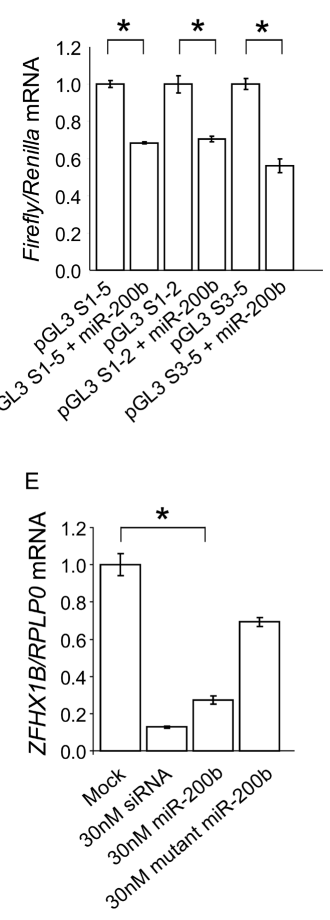

FIGURE 3. (Legend on next page) 
In conclusion, we find that miR-200b is a potent regulator of ZFHX1B expression via binding to multiple sites in the $3^{\prime}$-UTR. Consequently, exogenous miR-200b results in ZFHX1B repression, and inhibition of endogenous miR$200 \mathrm{~b}$ results in increased levels of ZFHX1B protein. The significance of the miR-200b:ZFHX1B interaction can furthermore be demonstrated using a promoter construct of the bona fide ZFHX1B target gene E-cadherin. Interestingly, we note that ZFHX1a ( $\delta E F 1)$, the other member of the ZFH-1 family, is also a predicted target of miR-200b. In addition, ZFHX1a and $-1 \mathrm{~b}$ are both predicted targets of miR-200c (Lewis et al. 2005; Griffiths-Jones et al. 2006). As ZFHX1a and -1b share several target genes, such as Brachyury and E-cadherin (Remacle et al. 1999), it is tempting to speculate that the miR-200 family has evolved to regulate the family of $\mathrm{ZFH}-1$ genes, possibly during processes of mesenchymal to epithelial transition, and control the containment of $\mathrm{ZFH}-1$ expression within specific cell types.

FIGURE 3. miR-200b regulates the $3^{\prime}$ UTR of $Z f h x l b$. (A) A luciferase reporter construct containing five miR-200b binding sites was cotransfected into HEK293 cells along with miR-200b, mutated miR-200b, or miR-10a. Five to $30 \mathrm{nM}$ miR-200b represssed the reporter $\left({ }^{*} P<0.001\right.$, Student's $t$-test). (Mock) Cells transfected with the luciferase reporter construct alone. Data are shown as mean $\pm S D$ of six or seven replicates and are representative of three independent experiments. (B) Analysis of individual miR-200b binding sites. Luciferase reporter constructs containing miR-200b binding sites $1-5,1-2$, or 3-5 were cotransfected into HEK293 cells with $10 \mathrm{nM}$ miR-200b or mutated miR-200b. As a control, the empty pGL3 vector was cotransfected with $10 \mathrm{nM}$ miR-200b. miR-200b repressed all of the reporters containing miR-200b binding sites $\left({ }^{*} P<0.001\right.$, Student's $t$-test) but not the empty vector. Data are shown as mean \pm SD of six or seven replicates and are representative of three independent experiments. (C) miR-200b reduces luciferase reporter mRNA levels. Luciferase reporter constructs containing miR-200b binding sites $1-5,1-2$, or $3-5$ were cotransfected into HEK293 cells with $10 \mathrm{nM}$ miR-200b. miR-200b caused a significant decrease in the mRNA level of all reporter constructs $\left({ }^{*} P<0.001\right.$, Student's $t$-test $)$. Data are shown as mean $\pm S D$ of three replicates and are representative of five independent experiments. (D) Endogenous ZFHX1B protein is regulated by miR-200b. MDA-MB-435S cells were transfected with $30 \mathrm{nM} Z F H X 1 B$ siRNA, miR-200b, mutated miR-200b, miR-10a, or an LNA inhibitor of miR-200b. Mock transfected cells were treated with transfection reagent alone. Forty-eight hours later, ZFHX1B levels were analyzed by Western blotting and the same blot was probed for Vincullin as a loading control. Quantification of the ZFHX1B expression relative to Vincullin is shown between the panels and referenced to the expression level in mock transfected cells. The blot is representative of three independent experiments. (E) miR-200b causes degradation of endogenous ZFHX1B mRNA. MDA-MB-435S cells were transfected with $30 \mathrm{nM} Z F H X 1 B$ siRNA, miR-200b, or mutated miR-200b. Mock transfected cells were treated with transfection reagent alone. miR-200b significantly reduced $Z F H X 1 B$ mRNA levels as determined by quantitative PCR $48 \mathrm{~h}$ after transfection $\left({ }^{*} P<0.001\right.$, Student's $t$-test). $Z F H X 1 B$ levels are shown relative to $R P L P 0$ and referenced to the $Z F H X 1 B / R P L P 0$ ratio in mock transfected cells. Data are shown as mean \pm SD of three replicates and are representative of three independent experiments.

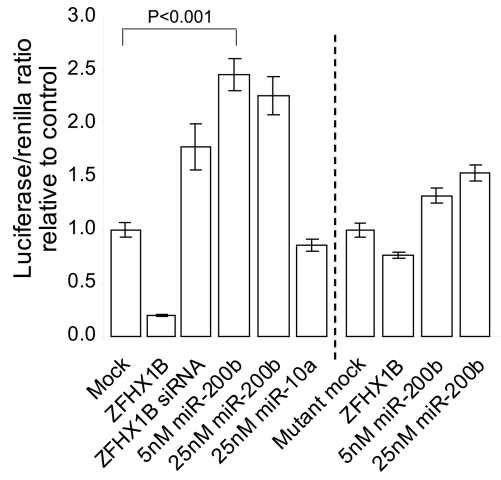

FIGURE 4. miR-200b increases E-cadherin promoter activity. A luciferase construct containing part of the human E-cadherin promoter, including the E-boxes, was cotransfected into HEK293 cells with $Z f h x 1 b$, siRNA against $Z F H X 1 B$, miR-200b, or miR-10a. miR$200 \mathrm{~b}$ derepressed the E-cadherin promoter construct $(P<0.001$, Student's $t$-test) whereas miR-10a did not. (Mock) cells transfected with the luciferase construct alone. As a control, a pGL2 construct with point mutations in the E-boxes of the E-cadherin promoter was cotransfected with $Z f h x 1 b$ or miR-200b (right part of figure). (Mutant mock) cells transfected with the mutated luciferase construct alone. Data are shown as mean \pm SD of six or seven replicates and are representative of three independent experiments.

\section{MATERIALS AND METHODS}

\section{Cell culture and transfections}

HEK293 cells were maintained in Dulbecco's modified Eagle's medium (DMEM) with 10\% FBS, $100 \mathrm{U} / \mathrm{mL}$ penicillin, and $100 \mu \mathrm{g} / \mathrm{mL}$ streptomycin and incubated at $5 \% \mathrm{CO}_{2}$ and $37^{\circ} \mathrm{C}$.

All transfections were carried out with Lipofectamine 2000 (Invitrogen) according to the manufacturer's instructions. For $Z f h x 1 b$ luciferase assays, HEK293 cells were seeded $1 \times 10^{4}$ per 96-well the day prior to transfection with $0.15 \mu \mathrm{g}$ luciferase expression construct, 2.5-30 nM miRNA duplex, and $0.015 \mu \mathrm{g}$ Renilla luciferase vector pRL-TK (Promega) for normalization. For E-cadherin luciferase assays, HEK293 cells were transfected with $0.1 \mu \mathrm{g}$ luciferase expression construct, $0.1 \mu \mathrm{g} Z f h \times 1 b$ expression construct, $50 \mathrm{nM}$ siRNA, 5-25 nM miRNA duplex, and $0.015 \mu \mathrm{g}$ pRL-TK for normalization. Mock transfected cells were transfected with the luciferase constructs alone. Luciferase activity was measured $48 \mathrm{~h}$ after transfection using the Dual-Glo Luciferase kit (Promega). For quantitative RT-PCR, HEK293 cells were seeded 400,000 per 6-well the day prior to transfection with $1.5 \mu \mathrm{g}$ luciferase expression construct, $0.15 \mu \mathrm{g} \mathrm{pRL}-\mathrm{TK}$, and $10 \mathrm{nM}$ miRNA duplex.

MDA-MB-435S cells were maintained in DMEM with $10 \%$ FBS, $10 \mu \mathrm{g} / \mathrm{mL}$ insulin, $100 \mathrm{U} / \mathrm{mL}$ penicillin, and $100 \mu \mathrm{g} / \mathrm{mL}$ streptomycin. For Western blotting and quantitative RT-PCR, MDA-MB-435S cells were seeded 400,000 per 6-well the day prior to transfection with $30 \mathrm{nM}$ miRNA, LNA, or siRNA using Lipofectamine 2000 (Invitrogen). Mock transfected cells were treated with transfection reagent alone. Transfections were repeated after $24 \mathrm{~h}$, and the cells were harvested $72 \mathrm{~h}$ after the first transfection. siGENOME SMARTpool siRNA against ZFHX1B were used (Dharmacon). 


\section{Plasmid vectors}

A multiple cloning site was inserted into the pGL3 control vector (Invitrogen) at the XbaI site $3^{\prime}$ of the luciferase gene (hereafter pGL3). A 1-kb fragment of the Zfhxilb 3' UTR (corresponding to positions 3979-5018 of the Ensembl transcript ENSMUST00000076836) was PCR amplified from mouse genomic DNA and cloned into pGL3. Four different constructs were made, each containing two or more of the five potential miR-200b binding sites present in the Zfhxlb 3' UTR (the binding sites referred to as S1 to S5 as illustrated in Fig. 1). The primer sequences used for PCR amplification were as follows (restriction sites indicated in lower case):

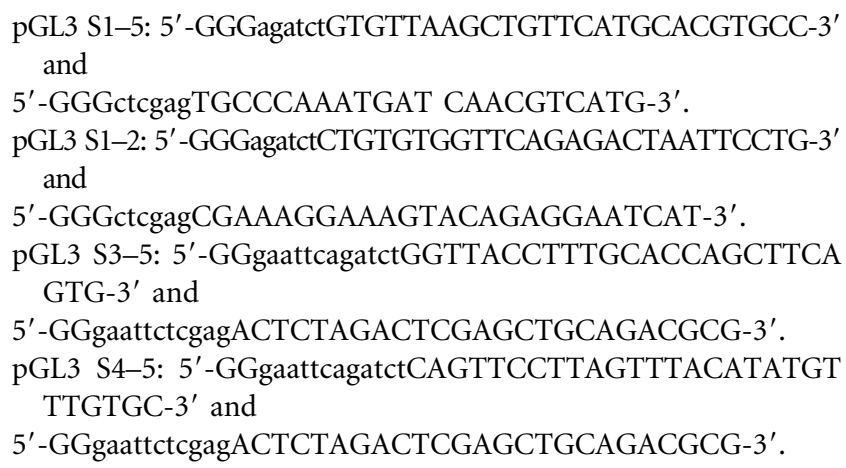

For E-cadherin luciferase assays we used a pGL2 vector with an insert upstream of the luciferase gene corresponding to position -108 to +119 of the human E-cadherin gene (Ensembl gene ID ENSG00000039068) in which two E-boxes are located (CACCTG/ CAGGTG). The mutated version of this construct carries point mutations in the E-box sequences (AACCTA/AAGGTA) (Grooteclaes and Frisch 2000).

\section{miRNA duplexes and anti-miRNA oligonucleotides}

miRNA duplexes with the following sequences were synthesized by CureVac:

miR-200b (sense): 5' - $\mathrm{PO}_{4}$-UAAUACUGCCUGGUAAUGAUGAC-3', miR-200b (guide): $5^{\prime}$ - $\mathrm{PO}_{4}$-CAUCAUUACCAGGCAGUAUUAAA-3', mutated $m i R-200 b$ (sense): 5' - $\mathrm{PO}_{4}$-UACUAGUGCCUGGUAAU GAUGAC-3',

mutated $m i R-200 b$ (guide): 5' - $\mathrm{PO}_{4}$-CAUCAUUACCAGGCAUU GGUAAA-3',

miR10a (sense): 5' - $\mathrm{PO}_{4}$-UACCCUGUAGAUCCGAAUUUGUG-3', miR10a (guide): 5' - $\mathrm{PO}_{4}$-CAAAUUCGGAUCUACAAAGUAAA-3'.

The LNA-modified oligonucleotide used for miR-200b inhibition and the LNA probe for in situ hybridization was purchased from Exiqon.

\section{Fluorescent in situ hybridization}

In situ detection of miR-200b was performed on $10-\mu \mathrm{m}$ frozen tissue sections from adult mouse brain. Sections were fixed in $4 \%$ paraformaldehyde and acetylated in acetic anhydride/triethanolamine, each followed by washes in PBS. Sections were then prehybridized in hybridization solution $(50 \%$ formamide, $5 \times$ SSC, $0.5 \mathrm{mg} / \mathrm{mL}$ yeast tRNA, $1 \times$ Denhardt's solution) at $48^{\circ} \mathrm{C}$ for $30 \mathrm{~min}$. Three-picomole probe (LNA-modified oligonucleotide,
Exiqon) complementary to $m i R-200 b$ was DIG-labeled (DIG Oligonucleotide 3' Tailing Kit, Roche Applied Sciences) and hybridized to the sections for $1 \mathrm{~h}$ at $48^{\circ} \mathrm{C}$. After post-hybridization washes in $0.1 \times \mathrm{SSC}$ at $55^{\circ} \mathrm{C}$, the in situ hybridization signals were detected using the tyramide signal amplification system (Perkin Elmer) according to the manufacturer's instructions. Slides were mounted in Prolong Gold containing DAPI (Invitrogen) and analyzed with an Olympus MVX10 microscope equipped with a CCD camera and Olympus CellP software.

\section{Real-time quantitative PCR}

Total RNA was Trizol purified, DNase digested, and reverse transcribed (TaqMan reverse transcription reagents) followed by quantitative PCR using Sybrgreen PCR Master Mix and the 7300 Real-Time PCR system (Applied Biosystems). The primer sequences used for human $Z F H X 1 B$ and RPLPO (ribosomal protein, large, $\mathrm{P} 0$ ) gene were

hSip 861F: 5' -GACCGCAATTAACAATGGTACAGTG-3', hSip 952R: 5' -CATCGCGTTCCTCCAGTTTTC-3', RPLP0 F: 5' -TTCATTGTGGGAGCAGAC-3', and RPLP0 R: 5'-CAGCAGTTTCTCCAGAGC-3'.

For the Renilla and firefly luciferase genes, the primer sequences were

Renilla F2: 5'-GGCCATGATTGGGGTGCTTGTT-3', Renilla R2: 5'-GGCCATTCATCCCATGATTCAATC-3', Luc 900F: 5'-TGTCGCTCTGCCTCATAGAACTG-3', and Luc 1016R: 5'-CCGTGATGGAATGGAACAACACT-3'.

\section{Antibodies and Western blot analysis}

A polyclonal antibody was raised against mouse and human ZFHX1B protein by immunization of rabbits with an oligopeptide (CDGHAVSIEEYLQRS) and affinity purified using Sulfolink Coupling Gel (Pierce).

MDA-MB-435S cells were harvested $72 \mathrm{~h}$ after the first transfection, washed once in PBS, and lysed in RIPA buffer $(150 \mathrm{mM}$ $\mathrm{NaCl}, 1 \% \mathrm{NP} 40,0.5 \%$ sodium deoxycholate, $0.1 \%$ SDS, $50 \mathrm{mM}$ Tris$\mathrm{HCl}$ at $\mathrm{pH} 8,2 \mathrm{mM}$ EDTA) containing $1 \mathrm{mM}$ DTT and $1 \times$ Pefabloc (Roche). Twenty micrograms of protein per lane were separated on an $8 \%$ polyacrylamide gel and transferred to a nitrocellulose membrane. Anti-ZFHX1B was used at a 1:500 dilution, and the hVIN-1 vincullin antibody (Sigma) was used at 1:20,000.

\section{ACKNOWLEDGMENTS}

We thank Lisa Frankel for critically reading the manuscript. Work in the authors' laboratories is supported by the Biotech Research and Innovation Centre, the Vilhelm Pedersen and Hustrus Foundation, The Danish Medical Research Council, the Danish Cancer Research Foundation, the Danish Cancer Society, the Association for International Cancer Research, the Lundbeck Foundation and the Danish National Advanced Technology Foundation.

Received March 29, 2007; accepted May 8, 2007. 


\section{REFERENCES}

Allen Brain Atlas. 2004. Seattle, WA: Allen Institute for Brain Science. http://www.brain-map.org.

Ambros, V. 2004. The functions of animal microRNAs. Nature 431: 350-355.

Bagga, S., Bracht, J., Hunter, S., Massirer, K., Holtz, J., Eachus, R., and Pasquinelli, A.E. 2005. Regulation by let-7 and lin-4 miRNAs results in target mRNA degradation. Cell 122: 553-563.

Bassez, G., Camand, O.J., Cacheux, V., Kobetz, A., Dastot-Le Moal, F., Marchant, D., Catala, M., Abitbol, M., and Goossens, M. 2004. Pleiotropic and diverse expression of ZFHX1B gene transcripts during mouse and human development supports the various clinical manifestations of the "Mowat-Wilson" syndrome. Neurobiol. Dis. 15: 240-250.

Bohnsack, M.T., Czaplinski, K., and Gorlich, D. 2004. Exportin 5 is a RanGTP-dependent dsRNA-binding protein that mediates nuclear export of pre-miRNAs. RNA 10: 185-191.

Cacheux, V., Dastot-Le Moal, F., Kaariainen, H., Bondurand, N., Rintala, R., Boissier, B., Wilson, M., Mowat, D., and Goossens, M. 2001. Loss-of-function mutations in SIP1 Smad interacting protein 1 result in a syndromic Hirschsprung disease. Hum. Mol. Genet. 10: 1503-1510.

Cai, X., Hagedorn, C.H., and Cullen, B.R. 2004. Human microRNAs are processed from capped, polyadenylated transcripts that can also function as mRNAs. RNA 10: 1957-1966.

Cohen, S.M., Brennecke, J., and Stark, A. 2006. Denoising feedback loops by thresholding-a new role for microRNAs. Genes \& Dev. 20: $2769-2772$.

Comijn, J., Berx, G., Vermassen, P., Verschueren, K., van Grunsven, L., Bruyneel, E., Mareel, M., Huylebroeck, D., and van Roy, F. 2001. The two-handed E box binding zinc finger protein SIP1 downregulates E-cadherin and induces invasion. Mol. Cell 7: 1267-1278.

Dastot-Le Moal, F., Wilson, M., Mowat, D., Collot, N., Niel, F., and Goossens, M. 2007. ZFHX1B mutations in patients with MowatWilson syndrome. Hum Mutat. 28: 313-321.

Doench, J.G. and Sharp, P.A. 2004. Specificity of microRNA target selection in translational repression. Genes \& Dev. 18: 504-511.

Elbashir, S.M., Martinez, J., Patkaniowska, A., Lendeckel, W., and Tuschl, T. 2001. Functional anatomy of siRNAs for mediating efficient RNAi in Drosophila melanogaster embryo lysate. EMBO J. 20: 6877-6888.

Elloul, S., Elstrand, M.B., Nesland, J.M., Trope, C.G., Kvalheim, G., Goldberg, I., Reich, R., and Davidson, B. 2005. Snail, Slug, and Smad-interacting protein 1 as novel parameters of disease aggressiveness in metastatic ovarian and breast carcinoma. Cancer 103: 1631-1643.

Griffiths-Jones, S., Grocock, R.J., van Dongen, S., Bateman, A., and Enright, A.J. 2006. miRBase: microRNA sequences, targets and gene nomenclature. Nucleic Acids Res. 34: D140-D144.

Grooteclaes, M.L. and Frisch, S.M. 2000. Evidence for a function of $\mathrm{CtBP}$ in epithelial gene regulation and anoikis. Oncogene 19: 38233828 .

Higashi, Y., Maruhashi, M., Nelles, L., Van de Putte, T., Verschueren, K., Miyoshi, T., Yoshimoto, A., Kondoh, H., and Huylebroeck, D. 2002. Generation of the floxed allele of the SIP1 (Smad-interacting protein 1) gene for Cre-mediated conditional knockout in the mouse. Genesis 32: 82-84.

Hornstein, E. and Shomron, N. 2006. Canalization of development by microRNAs. Nat. Genet. (Suppl.) 38: S20-S24.

Humphreys, D.T., Westman, B.J., Martin, D.I., and Preiss, T. 2005. MicroRNAs control translation initiation by inhibiting eukaryotic initiation factor $4 \mathrm{E} / \mathrm{cap}$ and poly(A) tail function. Proc. Natl. Acad. Sci. 102: 16961-16966.

Hutvagner, G., McLachlan, J., Pasquinelli, A.E., Balint, E., Tuschl, T., and Zamore, P.D. 2001. A cellular function for the RNAinterference enzyme Dicer in the maturation of the let-7 small temporal RNA. Science 293: 834-838.
Jackson, R.J. and Standart, N. 2007. How do microRNAs regulate gene expression? Sci. STKE 367: re1.

Jing, Q., Huang, S., Guth, S., Zarubin, T., Motoyama, A., Chen, J., Di Padova, F., Lin, S.C., Gram, H., and Han, J. 2005. Involvement of microRNA in AU-rich element-mediated mRNA instability. Cell 120: 623-634.

Ketting, R.F., Fischer, S.E., Bernstein, E., Sijen, T., Hannon, G.J., and Plasterk, R.H. 2001. Dicer functions in RNA interference and in synthesis of small RNA involved in developmental timing in C. elegans. Genes \& Dev. 15: 2654-2659.

Kim, V.N. and Nam, J.W. 2006. Genomics of microRNA. Trends Genet. 22: 165-173.

Lee, Y., Ahn, C., Han, J., Choi, H., Kim, J., Yim, J., Lee, J., Provost, P., Radmark, O., Kim, S., et al. 2003. The nuclear RNase III Drosha initiates microRNA processing. Nature 425: 415-419.

Lee, Y., Kim, M., Han, J., Yeom, K.H., Lee, S., Baek, S.H., and Kim, V.N. 2004. MicroRNA genes are transcribed by RNA polymerase II. EMBO J. 23: 4051-4060.

Lewis, B.P., Burge, C.B., and Bartel, D.P. 2005. Conserved seed pairing, often flanked by adenosines, indicates that thousands of human genes are microRNA targets. Cell 120: 15-20.

Lund, E., Guttinger, S., Calado, A., Dahlberg, J.E., and Kutay, U. 2004. Nuclear export of microRNA precursors. Science 303: 95-98.

Maeda, G., Chiba, T., Okazaki, M., Satoh, T., Taya, Y., Aoba, T., Kato, K., Kawashiri, S., and Imai, K. 2005. Expression of SIP1 in oral squamous cell carcinomas: Implications for E-cadherin expression and tumor progression. Int. J. Oncol. 27: 15351541.

Miyoshi, A., Kitajima, Y., Sumi, K., Sato, K., Hagiwara, A., Koga, Y., and Miyazaki, K. 2004. Snail and SIP1 increase cancer invasion by upregulating MMP family in hepatocellular carcinoma cells. $\mathrm{Br}$. J. Cancer 90: 1265-1273.

Petersen, C.P., Bordeleau, M.E., Pelletier, J., and Sharp, P.A. 2006. Short RNAs repress translation after initiation in mammalian cells. Mol. Cell 21: 533-542.

Pillai, R.S. 2005. MicroRNA function: Multiple mechanisms for a tiny RNA? RNA 11: 1753-1761.

Pillai, R.S., Bhattacharyya, S.N., Artus, C.G., Zoller, T., Cougot, N., Basyuk, E., Bertrand, E., and Filipowicz, W. 2005. Inhibition of translational initiation by Let-7 microRNA in human cells. Science 309: 1573-1576.

Postigo, A.A. 2003. Opposing functions of ZEB proteins in the regulation of the TGF $\beta / B M P$ signaling pathway. $E M B O$ J. 22: 2443-2452.

Remacle, J.E., Kraft, H., Lerchner, W., Wuytens, G., Collart, C., Verschueren, K., Smith, J.C., and Huylebroeck, D. 1999. New mode of DNA binding of multi-zinc finger transcription factors: $\delta E F 1$ family members bind with two hands to two target sites. EMBO J. 18: 5073-5084.

Rosivatz, E., Becker, I., Specht, K., Fricke, E., Luber, B., Busch, R., Hofler, H., and Becker, K.F. 2002. Differential expression of the epithelial-mesenchymal transition regulators snail, SIP1, and twist in gastric cancer. Am. J. Pathol. 161: 1881-1891.

Shook, D. and Keller, R. 2003. Mechanisms, mechanics and function of epithelial-mesenchymal transitions in early development. Mech. Dev. 120: 1351-1383.

Van de Putte, T., Maruhashi, M., Francis, A., Nelles, L., Kondoh, H., Huylebroeck, D., and Higashi, Y. 2003. Mice lacking ZFHX1B, the gene that codes for Smad-interacting protein-1, reveal a role for multiple neural crest cell defects in the etiology of Hirschsprung disease-mental retardation syndrome. Am. J. Hum. Genet. 72: 465470.

Verschueren, K., Remacle, J.E., Collart, C., Kraft, H., Baker, B.S., Tylzanowski, P., Nelles, L., Wuytens, G., Su, M.T., Bodmer, R., et al. 1999. SIP1, a novel zinc finger/homeodomain repressor, interacts with Smad proteins and binds to $5^{\prime}$-CACCT sequences in candidate target genes. J. Biol. Chem. 274: 20489-20498.

Wakamatsu, N., Yamada, Y., Yamada, K., Ono, T., Nomura, N., Taniguchi, H., Kitoh, H., Mutoh, N., Yamanaka, T., Mushiake, K., 


\section{Christoffersen et al.}

et al. 2001. Mutations in SIP1, encoding Smad interacting protein-1, cause a form of Hirschsprung disease. Nat. Genet. 27: 369-370.

Wang, B., Love, T.M., Call, M.E., Doench, J.G., and Novina, C.D. 2006. Recapitulation of short RNA-directed translational gene silencing in vitro. Mol. Cell 22: 553-560.

Wu, L., Fan, J., and Belasco, J.G. 2006. MicroRNAs direct rapid deadenylation of mRNA. Proc. Natl. Acad. Sci. 103: 4034-4039.

Yamada, K., Yamada, Y., Nomura, N., Miura, K., Wakako, R., Hayakawa, C., Matsumoto, A., Kumagai, T., Yoshimura, I.,
Miyazaki, S., et al. 2001. Nonsense and frameshift mutations in ZFHX1B, encoding Smad-interacting protein 1, cause a complex developmental disorder with a great variety of clinical features. Am. J. Hum. Genet. 69: 1178-1185.

Yekta, S., Shih, I.H., and Bartel, D.P. 2004. MicroRNA-directed cleavage of HOXB8 mRNA. Science 304: 594-596.

Yi, R., Qin, Y., Macara, I.G., and Cullen, B.R. 2003. Exportin-5 mediates the nuclear export of pre-microRNAs and short hairpin RNAs. Genes \& Dev. 17: 3011-3016. 

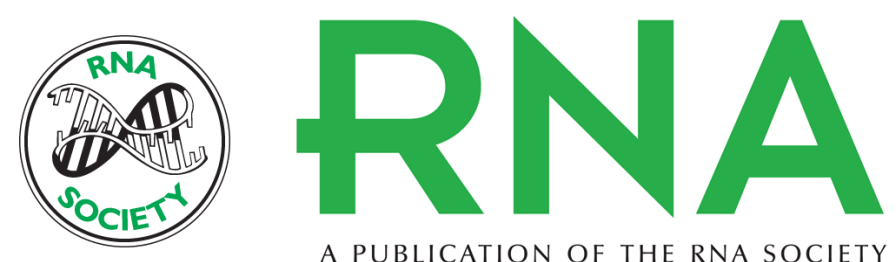

A PUBLICATION OF THE RNA SOCIETY

\section{miR-200b mediates post-transcriptional repression of ZFHX1B}

Nanna Rønbjerg Christoffersen, Asli Silahtaroglu, Ulf Andersson Ørom, et al.

RNA 2007 13: $1172-1178$ originally published online June 21, 2007

Access the most recent version at doi:10.1261/rna.586807

\section{References This article cites 42 articles, 18 of which can be accessed free at: http://rnajournal.cshlp.org/content/13/8/1172.full.html\#ref-list-1}

\section{License}

Email Alerting Receive free email alerts when new articles cite this article - sign up in the box at the Service top right corner of the article or click here. 